ORION, Vol. 12, No. 1/2, pp. 15-20

ISSN 0259-191-X

\title{
NUMBERS FOR THE RDP: THE ROLE OF THE CSS
}

\author{
JP LYNCH \\ Central Statistical Service
}

"A true and accurate knowledge of the numbers of its subject is indispensable to a legislative authority, both for assessing its strength in agriculture, trade and defence, and in suiting its measures and its policy thereto. And there is no means by which a government can gain the cardinal advantage knowing itself and its strength but by counting its subjects."

$J$ A von Lantingshausen (1746)

\section{INTRODUCTION}

The theme of this seminar brings to mind the original meaning of the word "statistics", namely numerical information about the State (i.e. state-istics). The word originated almost exactly two hundred years ago in a period which saw the formation of the first national statistical office and the inclusion in a constitution of a provision which bases the number of parliamentary representatives on the results of a population census.

The Central Statistical Service (CSS) is a government body (similar in most respects to a Department) which operates in terms of the Statistics Act, 1976 (Act No. 66 of 1976), subject to the directions of the Minister without Portfolio.

To perform its function of collecting, processing and publishing statistics, the CSS has an annual budget of about R50 million (with additional funding for surveys such as the Population Census) and a staff complement of 660 of whom approximately 100 are graduates in fields such as Statistics and 
Economics. These figures do not yet take account of the rationalisation with the statistical offices of the former TBVC states.

\section{WHAT CAN THE RDP DO FOR THE CSS}

The RDP is directly affecting the CSS in many ways:

- A greater emphasis is being placed on statistics covering those parts of our society which were covered poorly or not at all in the past.

- Consultation with stakeholders is being extended to include those who were not invited to participate in Advisory Committees or who would not participate for political reasons.

- he provision of information to individual communities by means of user friendly, specially tailored publications and the appointment of local liaison officers is being considered.

- Steps are being taken to make the CSS a more truly representative sample of our society.

An indirect but very real benefit to the CSS of the RDP is its insistence on measurement. The CSS is fully aware of the value of official statistics, not only as an important tool for government planning and administration but also as an instrument which allows voters to evaluate their democratically elected rulers. This awareness has not always been manifest in the past but can be seen in the assignment of the CSS to the Minister responsible for the RDP in the Office of the President. It could also lead to the allocation of more resources to this function which is seriously understaffed by international standards.

\section{WHAT CAN THE CSS DO FOR THE RDP}

Because of their focus on individuals and households there are two surveys which are of particular importance to the RDP, in terms of the data that they provide for analysis and for the monitoring of progress with implementation. These are the annual October Household Survey and the 1996 Population 
Census. The questionnaires for both surveys have been extensively adapted in consultation with stakeholders and the sample of the former has been redesigned, using small clusters, in order to permit a greater regional disaggregation of the results. The principle of "piggy-backing" more specific surveys onto the general purpose household survey has been accepted and, for 1995, detailed income and expenditure data will be collected.

A perusal of the RDP base document (which provides, in the words of the White Paper, "a guide to action and a checklist of performance") reveals that many of the remaining 120 statistical series produced by the CSS will also be required for the RDP.

A number of challenges remain, either for the CSS or for researchers in other fields.

These include:

- the measurement of some of the less tangible goals listed in the base document;

- developing methods to obtain some overall sense of progress;

- refining the United Nations Development Programme's Human Development Index which has been put forward as an overall measure of impact; and

- undertaking the kind of research which will guide the allocation of funds and other resources to competing programmes of the RDP.

It should be noted that national statistical offices generally do not undertake research or analysis lother than that related to the methods used to produce statistics) and do not go beyond interpretation, i.e. putting into words that which the statistics reveal. 


\section{ENSURING THAT STATISTICS ARE TIMELY, RELEVANT AND RELIABLE}

For official statistics to be useful to the RDP or for any other purpose, three key requirements must be satisfied.

\subsection{Timely statistics}

For a given allocation of resources, timeliness is dependant on efficiency and effectiveness. The CSS continues to seek optimum methods for collecting, processing and publishing statistics. So, for example, it has replaced batch data capturing and editing procedures with interactive systems. The statistics produced are also regularly reviewed to ensure that non-essential series are discontinued so that more resources can be allocated to those that are essential, or to new series.

\subsection{Relevant statistics}

The notion of relevance implies that the statistics must serve a purpose. The purpose must, moreover, be one that is national or general, in keeping with the CSS's role as national statistical office. (The theory of public goods provides a framework within which individual cases can be considered).

If a national statistical system is to produce the information that society needs, such needs must be identified and the users of statistics have a heavy responsibility in this respect since it is incumbent on them to specify the problems for which the statistics are expected to provide a solution. But statisticians should not restrict themselves to the production phase since, by becoming involved with users, they will be able to enhance their understanding of the problems to be addressed (and in so doing provide optimal solutions). They will also be able to ensure that users pay proper attention to the limitations of the statistics.

The RDP goes a long way towards providing not only a purpose for the statistics but also a detailed list of specific items for which statistics are 
required. A large proportion of the requirements can be met from the statistics routinely produced by the CSS or require only fairly minor modification of existing questionnaires or survey methods. An examination of the list also reveals area (such as environmental statistics and information on human rights) for which little or no suitable data is available and these gaps will have to be addressed.

The fact that resources are limited and that the demand for statistics (whether for the RDP or for the Minister's colleagues in the Cabinet) is virtually unlimited, leads to the problem of setting priorities. That this is not an easy problem can be seen from the following:

- Since official statistics are public goods there is no market mechanism which produces prices to aid in making decisions.

- Not all users are of equal importance which rules out "selection by voting".

- The cost of not having particular statistics or of having only poor statistics cannot be determined.

\subsection{Reliable statistics}

In discussing the reliability of the statistics produced by a national statistical office, the first question is whether any government can be trusted to provide impartial information about its successes and failures. Since there are several good reasons why the production of statistics cannot be left to private enterprise or, even, be contracted out to commercial researchers, many countries have introduced systems to isolate the official statisticians from the influence of politicians while attempting to retain political accountability. Such systems range from the use of written instructions to the responsible Minister to maintain an arm's length relationship with the statistics office (as in the case in Canada), to the appointment of managerial or advisory boards. The South African Statistics Act makes provision of an advisory council which is intended to act as watchdog over the interests of the various stakeholders, namely the 
politicians, taxpayers and other users, the respondents who provide the basic information and the statisticians themselves. The legislation governing the establishment and operation of the Statistic Council is, itself, the focus of an RDP project.

The use of sound methodology is a further necessary condition for reliable statistics. International agencies (the statistical offices of the United Nations and the ILO, in particular) provide detailed recommendations which are invaluable. Scientific papers published in statistical journals (especially those devoted to official statistics) or presented at conferences (such as those of the International Statistical Institute) contain research results, descriptions of methods applied in other statistical offices and discussion of important issues of principle. These are valuable additions to the research carried out in the CSS.

The capacity of a statistical office to produce the statistics that are required of it obviously impacts on reliability since effort must be expended to design, produce and evaluate thoroughly. Resource constraints can also force a tradeoff between reliability and timeliness.

The ultimate test of reliability results from the fact that a statistical office publishes its statistics for public scrutiny. Where such figures do not accord with other data made available by the CSS or other producers of statistics or tally with the knowledge or opinions of researchers or other experts, the CSS and the media are quick to hear.

\section{CONCLUSION}

The CSS is committed to serving the whole of South Africa, and the RDP in particular, with timely, relevant and reliable statistics. To this end it looks forward to a growing relationship with both the respondents on whom it depends for information and the users of the statistics that it provides. 